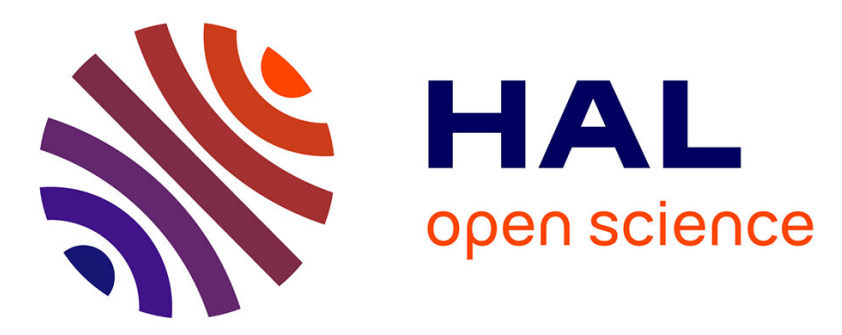

\title{
Fiber rupture in sheared planar pantographic sheets: Numerical and experimental evidence
}

Emilio Turco, Francesco Dell'Isola, Nicola Luigi Rizzi, Roman Grygoruk, Wolfgang H. Müller, Christian Liebold

\section{- To cite this version:}

Emilio Turco, Francesco Dell'Isola, Nicola Luigi Rizzi, Roman Grygoruk, Wolfgang H. Müller, et al.. Fiber rupture in sheared planar pantographic sheets: Numerical and experimental evidence. Mechanics Research Communications, 2016, 76, pp.86-90. 10.1016/j.mechrescom.2016.07.007 . hal-01354961

\author{
HAL Id: hal-01354961 \\ https://hal.science/hal-01354961
}

Submitted on 23 Aug 2016

HAL is a multi-disciplinary open access archive for the deposit and dissemination of scientific research documents, whether they are published or not. The documents may come from teaching and research institutions in France or abroad, or from public or private research centers.
L'archive ouverte pluridisciplinaire HAL, est destinée au dépôt et à la diffusion de documents scientifiques de niveau recherche, publiés ou non, émanant des établissements d'enseignement et de recherche français ou étrangers, des laboratoires publics ou privés. 


\title{
Fiber rupture in sheared planar pantographic sheets: Numerical and experimental evidence
}

\author{
Emilio Turco ${ }^{\mathrm{a}, \mathrm{d},{ }^{*}, \text { Francesco dell'Isola }} \mathrm{b}^{\mathrm{b}, \mathrm{d}}$, Nicola Luigi Rizzi ${ }^{\mathrm{c}, \mathrm{d}}$, Roman Grygoruk ${ }^{\mathrm{d}, \mathrm{e}}$, \\ Wolfgang H. Müller ${ }^{\mathrm{d}, \mathrm{f}}$, Christian Liebold ${ }^{\mathrm{d}, \mathrm{f}}$ \\ - University of Sassari. Araiy \\ bUniversity of Roma "La Sapienza", Italy \\ cRoma Tre University, Italy \\ a MEMOCS, Italy \\ 'Warsaw University of Technology. Poland \\ 'Technische Universitut Berlin, Germany
}

\author{
A B S T R A C T
}

Pantographic sheets are metamaterials showing some interesting mechanical features. The mechanical behavior of planar pantographic sheets has been studied by means of second gradient continuum models, see $[1,2]$. In $[3,4]$ an efficient numerical code has been developed by characterizing equilibrium configurations under imposed displacement boundary conditions as those minimizing a discrete Lagrangian deformation energy. Using this model, it is possible to design experimental setups and, qualitatively and quantitatively, predict the elastic behavior of specimens built by means of 3D printing technology. In the present paper we show the first available experimental evidence obtained for sheared pantographic specimens and we show how effective and predictive is the aforementioned code. Subsequently, a simple fiber rupture mechanism is postulated and added to the initially elastic model. By adding further constitutive parameters to the previous four elastic ones, the generalized numerical model is able to predict very well the observed rupture phenomena. The promising results obtained motivate further development of proposed numerical and theoretical models and the conception of more complex experimental setups.

\section{Introduction}

Metamaterials are materials which are conceived by means of a theoretical effort aimed to characterize their structure by means of the equations governing their behavior. To be more precise: once a given behavior is specified by means of a set of mathematical prescriptions to be verified, the corresponding metamaterial is characterized as that material whose behavior is exactly described (under specific conditions) by the initially chosen prescriptions. The problem to be solved in this context is, in a sense, an inverse

\footnotetext{
- Corresponding author.

E-mail addresses: emilio,turco@uniss. it (E Turco), francesco,dellisoląiniroma1_it (F. dell'lsola).

nicolaluigi.rizzieuniroma3 it (N.L. Rizzi), r.grygonukewip.pw.edu.pl (R. Grygoruk). Wolfgang.H.MuellereTU-Berlin. DE (W.H. Muller), christian.tiebolderu-berlin.de (C. Lebold)
}

problem. Given the governing equations (or conditions) one has to find and construct the material whose behavior is predicted by them. Sometimes in literature one talk about the problem of "synthesis": given the mathematical model, is it possible to synthesize a material described by it?

Pantographic sheets are metamaterials which have been synthesized [2,1] to prove the existence of bodies behaving as second gradient materials (see [5,6]). Indeed the mechanical behavior of planar pantographic sheets exhibits the onset of internal deformation boundary layers and interact with external constraints by means of "exotic" contact interactions, see [7].

In [3.4] an efficient numerical code has been developed to get a more expedite prediction, control and design of the behavior of pantographic sheets. The concept on which this code is based considers the characterization of the kinematics of the system by means of a discrete set of Lagrangian coordinates and introduces an internal potential energy to account for stored deformation energy. 


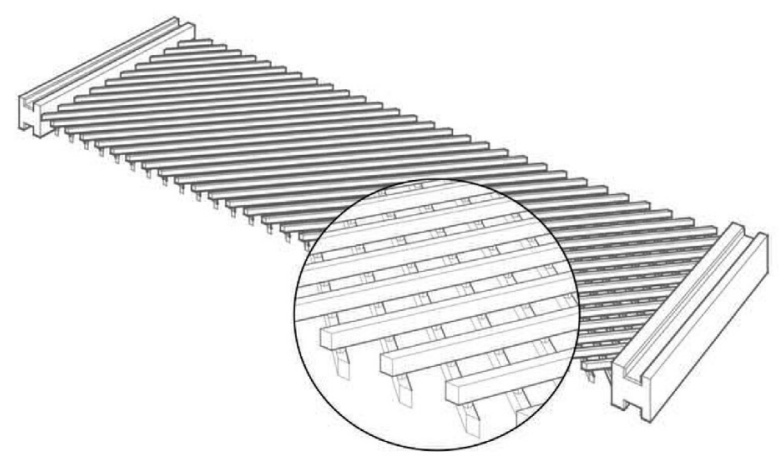

Fig. 1. Specimen constructed using 3D printing technology.

The equilibrium configurations under imposed (varying in dependence of a finite set of parameters) displacement boundary conditions are those configurations which minimize the just introduced discrete Lagrangian deformation energy.

The advantage presented by such an approach when compared with the other one based on the formulation of second gradient continuum model and its discretization with FEM can become evident in many situations. Indeed when the considered fabric does not include too many structural elements then the discretization which we propose here: (i) has a more direct physical meaning, (ii) is still able to effectively capture the global behavior of the system and (iii) is more computationally efficient.

Using the Lagrangian model presented here it has been possible to design experimental setups aimed to show the peculiar features of newly conceived metamaterial. Moreover we could qualitatively and quantitatively predict the elastic behavior of specimens built by means of 3D printing technology also in the regime of large geometrical and material nonlinearities.

In the following sections we show the first available experimental evidence obtained for sheared pantographic specimens: we designed a mechanism transforming imposed elongations into imposed shear deformations (see Fig. 1) and we characterized a large class of deformation states of pantographic sheets. Paralleling their behavior in extensional bias tests (see [2]) pantographic sheets are extremely tough also under large shear deformations. It can be shown that the code which we have developed is very effective and predictive in the elastic regime: we could get a complete correspondence between experimental data and numerical ones by simply fitting the four material parameters characterizing our model. These parameters are easily related to: (i) extensional fiber stiffness, (ii) bending fiber stiffness, (iii) shear stiffness related to fiber connectivity and (iv) material nonlinearity determining eventually non-quadratic shear deformation energy.

To be able to predict fiber rupture phenomena we subsequently postulated a simple fiber rupture mechanism. We assume that once a fiber experiences an elongation larger than a specific threshold (which is characteristic of the fiber constituting material) then it is simply broken, and the corresponding term in deformation energy is assumed to vanish. Therefore by simply adding a further constitutive parameter to the previously introduced four elastic ones we get a generalized incremental numerical model. When in the considered quasi-static imposed displacement process the rupture criterion is attained, then in the subsequent step the elastic energy is modified by imposing to zero the corresponding energy addend.

This simple model was able to predict very well the observed rupture phenomena, as it is described in the following Section 2. The results obtained and presented in Section 3 strongly motivate further development of proposed numerical and theoretical models: further rupture mechanism have been observed and need to be modeled, involving fiber interconnection rupture or partial or total loss of fiber bending stiffness, see Section 4 . The consequence of the further sophistication of the used models will lead to the conception of more complex experimental setups aimed to more careful characterization of the behavior of pantographic sheets.

\section{Lagrangian discrete model for pantographic structures}

As discussed in full detail in [3] Lagrangian discrete models can be a viable option in the description of pantographic sheets: the possibility to predict their shapes in large deformation equilibrium configurations using said discrete models has been the object of the investigations presented in [4]. Referring the reader to just cited papers for a detailed discussion of the model and the algorithmic procedure we use to determine equilibrium configurations, we delineate here the main ideas on which we base our solution strategy when dealing with both elastic and rupture deformation phenomena.

First of all, we limit our attention to quasi-static deformation processes where the control parameters determine a well-determined class of imposed boundary displacements. The principle of virtual work will allow a facile generalization of our formulation to the fully dynamic case. Second we introduce a finite dimensional configuration space to describe the kinematics of considered sheets: it is constituted by the collection of the positions of the pivots interconnecting the two arrays of fibers, each of them being assumed extensible and flexible.

The elastic deformation energy of the sheet is assumed to be given by the sum of terms respectively (see Fig. 2) accounting for: (i) extensional energy between two adjacent pivots, (ii) bending energy of the fibers and (iii) shear energy stored in the interconnecting pivots.

We limit ourselves to consider hard-devices imposing boundary displacements to the sheets: therefore the problem of finding the equilibrium configurations in a quasi-static deformation process

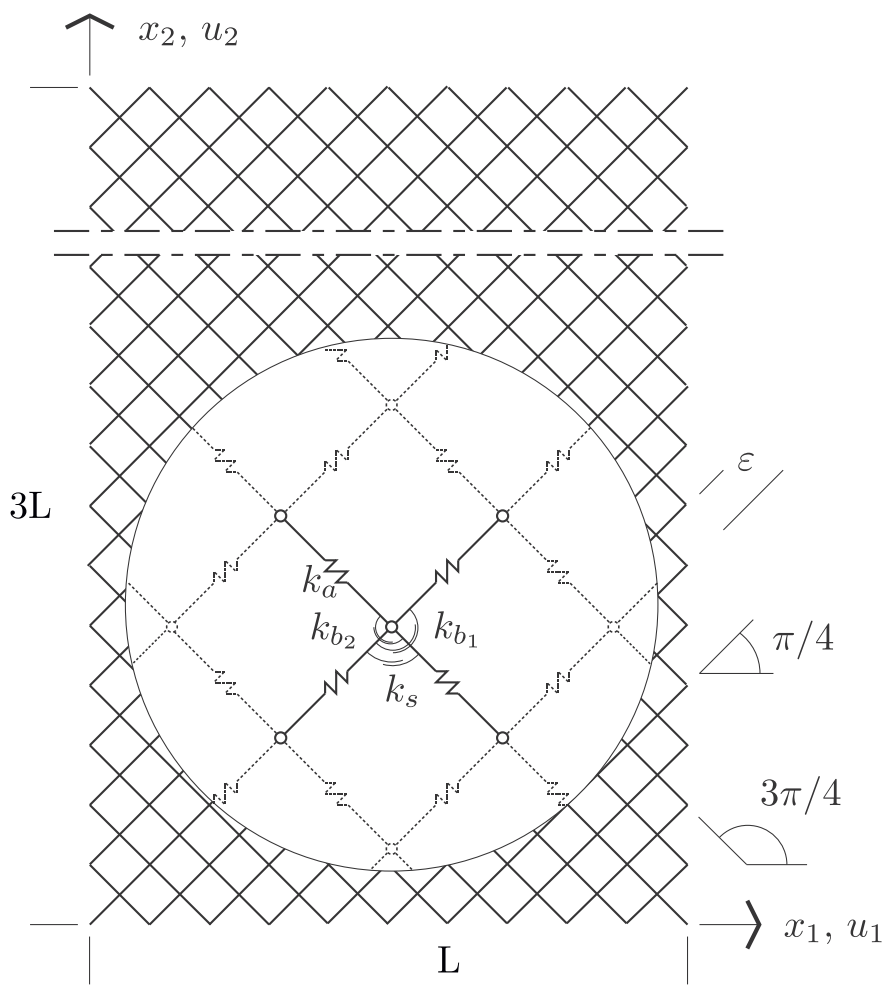

Fig. 2. Mechanical model of a pantographic 2D structure. 
reduces to the determination of the minima of deformation energy corresponding to the assigned values of the parameters characterizing the boundary conditions.

The algorithm which is successfully used here (following the ideas proposed in this context in [3]) handles the strong nonlinearities arising in the aforementioned minimization process by proceeding to calculate sequences of close equilibrium configurations relative to close boundary conditions. The relevant economy of calculation time is exploited also in the simulations we present here for elastic regimes. Not only: we start here from a wellgrounded simplifying assumption. We assume that fiber rupture occur only when a threshold elongation (or bending angle or shear angle) is attained in our quasi-static deformation process. These thresholds are easily estimated in terms of the constitutive parameters of the material used in the 3D printing which produced the specimens we have studied. The simple modification of the elastic energy consequent to a rupture consists in assuming as vanishing the corresponding addend in the deformation energy.

Synoptically, by referring to Fig. 2, strain energies and strain thresholds for each kind of spring are: (i) for an extensional spring whose stiffness is $k_{a}$

$E_{a}=\frac{1}{2} k_{a}(\ell-\varepsilon)^{2}$,

$a_{\min } \leq \frac{\ell-\varepsilon}{\varepsilon} \leq a_{\max }$,

where $\ell$ and $\varepsilon$ are the distances between two pivots in the actual and in the reference configuration, respectively; $a_{\min }$ and $a_{\max }$ are the minimum and maximum value of the elongation threshold, respectively; (ii) bending springs whose stiffness is $k_{b, i}$

$E_{b, i}=k_{b, i}\left(1+\cos \varphi_{i}\right), \quad i=1,2$,

$\cos \varphi_{i} \leq b_{\max , i}, \quad i=1,2$,

where $\varphi_{i}$ is the angle, in the actual configuration, between two consecutive fibers along $i$-direction; $b_{\mathrm{max}, i}$ is the maximum admissible value in $i$-direction; (iii) shear springs whose stiffness is $k_{S}$

$E_{s, i}=\frac{1}{2} k_{s}\left(\varphi_{i}-\frac{\pi}{2}\right)^{2}, \quad i=1, \ldots, 4$,

$\frac{\left|\varphi_{i}-\frac{\pi}{2}\right|}{\frac{\pi}{2}} \leq s_{\max }, \quad i=1, \ldots, 4$,

where $\varphi_{i}$ is, in the actual configuration, the angle, in the $i$-quadrant, between two unaligned fibers which share the same pivot; $s_{\max , j}$ is the maximum value of the admissible angle change.

\section{Numerical predictions versus experimental evidence for shear tests}

A polyamide specimen, constructed using 3D printing technology, with $\mathrm{L}=70 \mathrm{~mm}$ and $L / \varepsilon=10 \sqrt{2} \mathrm{~mm}$ was analyzed. The cross-section of the fibers is rectangular and has the width equal to $0.9 \mathrm{~mm}$ and the depth equal to $1.6 \mathrm{~mm}$. Pivots are cylinders whose diameter is $0.9 \mathrm{~mm}$ and whose height is $0.5 \mathrm{~mm}$. For the Young's modulus we chose the value $1600 \mathrm{MPa}$.

The specimen was deformed imposing, gradually, a horizontal displacement on the top of the specimen by using as loading device a MTS TYTRON-250 with a $250 \mathrm{~N}$ load cell. The experiment was displacement-controlled, more precisely a displacement-rate was defined and applied to the specimen through a DC-linear motor where an air-film-bearing realized almost frictionless movement. In order to reduce the influences of external vibration the system is arranged horizontally and also based on a massive substructure.

Fig. 3 reports two pictures taken, the first, at the beginning of the test (reference configuration) and, the second, exactly

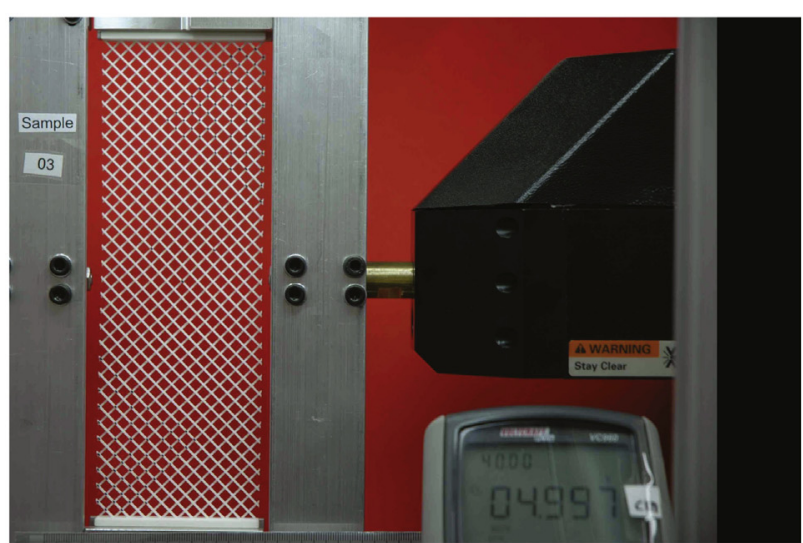

(a) Reference configuration $(\lambda=0)$.

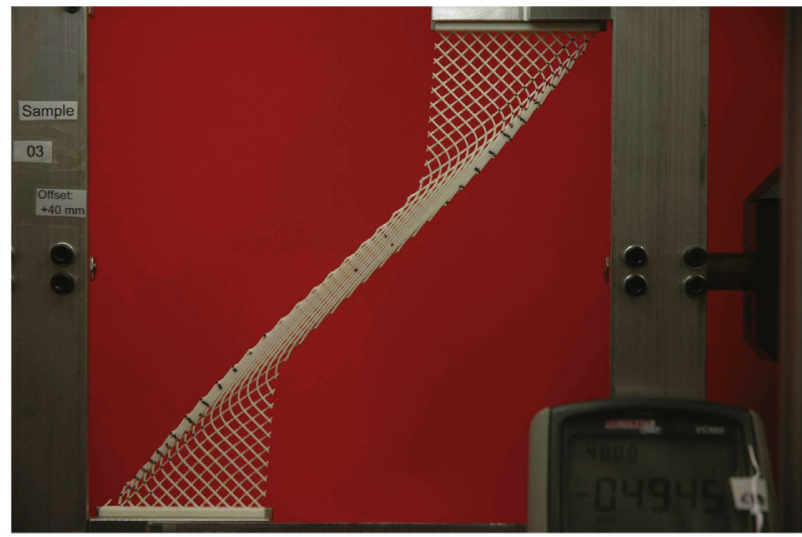

(b) Breakdown onset $(\lambda=0.976)$.

Fig. 3. Experimental shear test: reference configuration (a) and deformation corresponding to the breakdown onset (b) (the broken fiber is in the lower left).

immediately behind the rupture of the first fiber of the specimen, i.e. for a horizontal displacement of $139.96 \mathrm{~mm}$.

The numerical simulation presented below was performed assuming that the stiffnesses of the springs are: $k_{a}=134 \mathrm{~N} / \mathrm{mm}$,

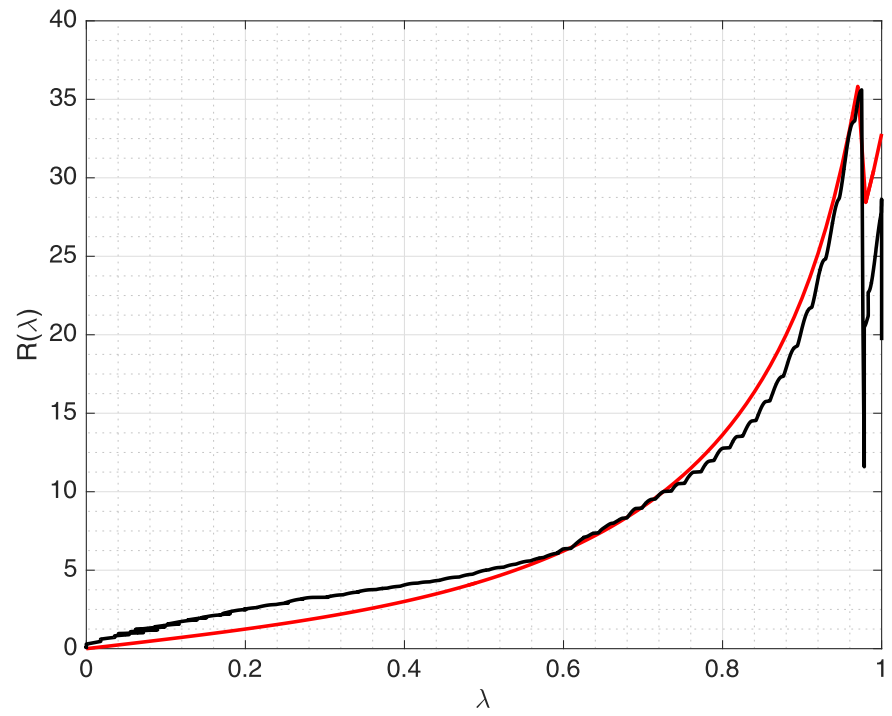

Fig. 4. Shear test: global structural reaction $R$ (in the direction of the imposed displacement) $v$ s. the non-dimensional displacement parameter $\lambda$, the black and red curves are related to the experiment and to the numerical calculations, respectively. 


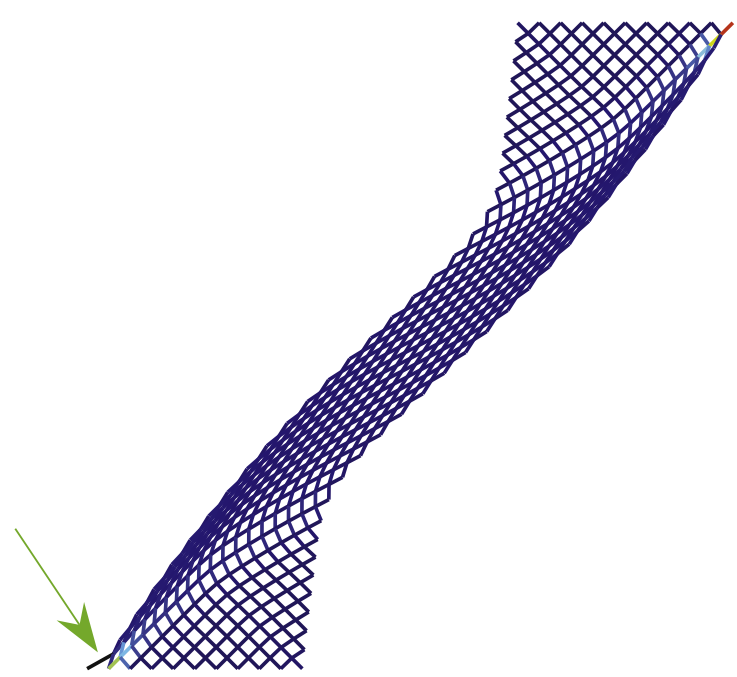

Fig. 5. Numerical shear test: deformation corresponding to the breakdown onset (the broken fiber is indicated in black and it is highlighted by an arrow). (For interpretation of the references to color in this figure legend, the reader is referred to the web version of the article.)

$k_{b, i}=19.2 \mathrm{Nmm}, k_{s}=0.69 \mathrm{Nmm}$ and the strain thresholds are: $a_{\min }=-0.99, a_{\max }=0.31, b_{\max , i}=1$ and $s_{\max , j}=1$.

Fig. 4 reports the global structural reaction $R$ (in the direction of the imposed displacement) versus the non-dimensional displacement parameter $\lambda$ (which attains a unit value when the maximum imposed displacement is reached); the black and red curves are related to the experiment and to the numerical calculations, respectively. We observe a remarkable closeness between the experimental measurements on structural reaction $R$ and the results of the numerical simulation.

Finally, Fig. 5 reports the deformation of the specimen immediately behind the rupture of the first fiber (depicted in black) and it is highlighted by a green arrow for clarity reasons. The colors in the plot represent the total strain energy level, from lower levels (cool tones, e.g. in blue) to higher ones (warm tones, e.g. in red).

\section{Conclusions}

Also in the case of the description of fiber rupture phenomena we could adapt the Lagrangian discrete model proposed in [3] to get efficiently predictive numerical simulations. The advantage of the presented numerical model can be resumed as follows: (i) it is able to produce easily results in the regime of large deformations and displacements, (ii) it is based on the best fit of a limited number of constitutive parameters (between five and seven) to all of which a clear physical meaning can be attributed, (iii) all aforementioned constitutive parameters are easily related to specific geometrical and mechanical properties of considered fabrics so that their value, in a specific situation and for a specific specimen, can be easily estimated to belong to a well-determined range, (iv) it seems to be easily generalizable to the study of dynamic regimes, where inertial forces may play a relevant role, see some insight in $[8,9]$.

The results which we present here have a twofold impact: (i) from the experimental point of view we prove that the relevant toughness in extension (proven in [2]) of pantographic sheets coexists with a similarly relevant toughness in presence of imposed shear deformations, (ii) from the theoretical point of view we prove that used Lagrangian discrete model is flexible enough to be able to incorporate a facile modification allowing for the efficient description of rupture phenomena.

It has to be remarked that even if pantographic structures were synthesized to give an example of second gradient metamaterial,

see e.g. [10-16], modeled as generalized continua, we prove here that, when some specific deformation phenomena are considered, the most suitable models are not continuous. On the other hand, as seen in $[1,17]$, when the qualitative description of their behavior is needed then second gradient continuum models may be more suitable.

Further investigations will produce a complete description of all rupture mechanism involving (and observed in) pantographic sheets among which we cite the fibers' detachments. Also the relevant effort of modeling out of plane deformation configurations and related buckling phenomena must be pursued, see the guidelines described, for example, in [18-27].

It seems somewhat interesting to build macro-springs obtained by using the capabilities of NURBS interpolation, see e.g. [28-35] in order to design new and enriched metamaterials. It is also very interesting the extension to the $3 \mathrm{D}$ case using the suggestions reported in [36].

Furthermore, the Hencky-type model briefly recalled here could be interesting also to model the granular media interactions, see [37], or generalized continua, see [10,38-41] for a general review and [42] for an application on masonry structures.

Finally, it deserves attention the identification of the parameters, i.e. the stiffnesses of the springs and the strain thresholds, used to build the numerical model since the performances of the model depend significantly on their values. In this perspective it is definitely helpful a sensitivity analysis on the parameters by using the tools reported, shortly, in the review paper [43] and, in depth, in [44-49] and applied in problems concerning huge and innovative structures as those described e.g. in $[50,51]$.

\section{References}

[1] F. dell'Isola, I. Giorgio, M. Pawlikowski, N.L. Rizzi, Large deformations of planar extensible beams and pantographic lattices: Heuristic homogenisation, experimental and numerical examples of equilibrium, Proc. R. Soc. Lond. A: Math. Phys. Eng. Sci. 472 (2185) (2016).

[2] F. dell'Isola, T. Lekszycki, M. Pawlikowski, R. Grygoruk, L. Greco, Designing a light fabric metamaterial being highly macroscopically tough under directional extension: first experimental evidence, Z. für Angew. Math. Phys. 66 (6) (2015) 3473-3498.

[3] E. Turco, F. dell'Isola, A. Cazzani, N.L. Rizzi, Hencky-type discrete model for pantographic structures: numerical comparison with second gradient continuum models, Z. für Angew. Math. Phys. 67 (4) (2016) 1-28.

[4] E. Turco, M. Golaszewski, A. Cazzani, N.L. Rizzi, Large deformations induced in planar pantographic sheets by loads applied on fibers: experimental validation of a discrete Lagrangian model, Mech. Res. Commun. 76 (2016) 51-56.

[5] J.-J. Alibert, P. Seppecher, F. dell'Isola, Truss modular beams with deformation energy depending on higher displacement gradients, Math. Mech. Solids 8 (1) (2003) 51-73.

[6] P. Seppecher, J.-J. Alibert, F. dell'Isola, Linear elastic trusses leading to continua with exotic mechanical interactions, J. Phys.: Conf. Ser. 319 (1) (2011) 012018 (IOP Publishing).

[7] F. dell'Isola, P. Seppecher, A. Madeo, How contact interactions may depend on the shape of Cauchy cuts in Nth gradient continua: approach "à la D'Alembert", Z. für Angew. Math. Phys. 63 (6) (2012) 1119-1141.

[8] A. Cazzani, F. Stochino, E. Turco, On the whole spectrum of Timoshenko beams. Part I: a theoretical revisitation, Z. für Angew. Math. Phys. (2016) 1-30, http://dx.doi.org/10.1007/s00033-015-0592-0.

[9] A. Cazzani, F. Stochino, E. Turco, On the whole spectrum of Timoshenko beams. Part II: further applications, Z. für Angew. Math. Phys. (2016) 1-21, http://dx.doi.org/10.1007/s00033-015-0596-9.

[10] F. dell'Isola, D. Steigmann, A. Della Corte, Synthesis of fibrous complex structures: designing microstructure to deliver targeted macroscale response, Appl. Mech. Rev. 67 (6) (2015) 060804.

[11] I. Giorgio, R. Grygoruk, F. dell'Isola, D.J. Steigmann, Pattern formation in the three-dimensional deformations of fibered sheets, Mech. Res. Commun. 69 (2015) 164-171.

[12] D. Scerrato, I. Giorgio, N.L. Rizzi, Three-dimensional instabilities of pantographic sheets with parabolic lattices: numerical investigations, Z. für Angew. Math. Phys. 67 (3) (2016) 1-19.

[13] D. Scerrato, I.A. Zhurba Eremeeva, T. Lekszycki, N.L. Rizzi, On the effect of shear stiffness on the plane deformation of linear second gradient pantographic sheets, Z. für Angew. Math. Mech. (2016), http://dx.doi.org/10. 1002/zamm.201600066. 
[14] M.V. D’Agostino, I. Giorgio, L. Greco, A. Madeo, P. Boisse, Continuum and discrete models for structures including (quasi-) inextensible elasticae with view to the design and modeling of composite reinforcements, Int. J. Solids Struct. 59 (2015) 1-17.

[15] L. Placidi, U. Andreaus, I. Giorgio, Identification of two-dimensional pantographic structure via a linear d4 orthotropic second gradient elastic model, J. Eng. Math. (2016), http://dx.doi.org/10.1007/s10665-016-9856-8.

[16] I. Giorgio, Numerical identification procedure between a micro cauchy model and a macro second gradient model for planar pantographic structures, $Z$. für Angew. Math. Mech. (2016), http://dx.doi.org/10.1007/s00033-016-0692-5.

[17] F. dell'Isola, U. Andreaus, L. Placidi, At the origins and in the vanguard of peridynamics, non-local and higher-gradient continuum mechanics: An underestimated and still topical contribution of Gabrio Piola, Math. Mech. Solids 20 (8) (2015) 887-928.

[18] S. Gabriele, N.L. Rizzi, V. Varano, On the imperfection sensitivity of thin-walled frames, in: B.H.V. Topping (Ed.), Proceedings of the Eleventh International Conference on Computational Structures Technology, vol. 99 Stirlingshire, UK, Civil-Comp Press, 2012, http://dx.doi.org/10.4203/ccp.99.15.

[19] M. Pignataro, G. Ruta, N.L. Rizzi, V. Varano, Effects of warping constraints and lateral restraint on the buckling of thin-walled frames, in: ASME International Mechanical Engineering Congress and Exposition, vol. 10, 2010, pp. 803-810.

[20] N. Rizzi, V. Varano, S. Gabriele, Initial postbuckling behavior of thin-walled frames under mode interaction, Thin-Walled Struct. 68 (2013) 124-134

[21] S. Gabriele, N. Rizzi, V. Varano, A 1D higher gradient model derived from Koiter's shell theory, Math. Mech. Solids (2014) 6.

[22] H. AminPour N. Rizzi, A one-dimensional continuum with microstructure for single-wall carbon nanotubes bifurcation analysis, Math. Mech. Solids 21 (2) (2016) 168-181.

[23] S. Gabriele, N.L. Rizzi, V. Varano, A 1D nonlinear TWB model accounting for in plane cross-section deformation, Int. J. Solids Struct. 94-95 (2016) 170-178.

[24] H. AminPour, N.L. Rizzi, On the continuum modelling of carbon nano tubes, in: J. Kruis, Y. Tsompanakis, B.H.V. Topping (Eds.), Proceedings of the Fifteenth International Conference on Civil, Structural and Environmental Engineering Computing, vol. 108, Stirlingshire, UK, Civil-Comp Press, 2015, http://dx.doi. org/10.4203/ccp.108.240.

[25] S. Gabriele, N.L. Rizzi, V. Varano, A one-dimensional nonlinear thin walled beam model derived from Koiter shell theory, in: B.H.V. Topping, P. Iványi (Eds.), Proceedings of the Twelfth International Conference on Computational Structures Technology, Stirlingshire, UK, Civil-Comp Press, 2014, http://dx. doi.org/10.4203/ccp.106.156.

[26] H. AminPour, N.L. Rizzi, G. Salerno, A one-dimensional beam model for single-wall carbon nano tube column buckling., in: B.H.V. Topping, P. Iványi (Eds.), Proceedings of the Twelfth International Conference on Computational Structures Technology, vol. 106, Stirlingshire, UK, Civil-Comp Press, 2014, http://dx.doi.org/10.4203/ccp.106.155.

[27] N.L. Rizzi, V. Varano, On the postbuckling analysis of thin-walled frames, in: B.H.V. Topping, Y. Tsompanakis (Eds.), Proceedings of the 13th International Conference on Civil, Structural and Environmental Engineering Computing, Stirlingshire, UK, Civil-Comp Press, 2011, http://dx.doi.org/10.4203/ccp.96.43.

[28] A. Cazzani, M. Malagù, E. Turco, Isogeometric analysis of plane curved beams, Math. Mech. Solids 21 (5) (2016) 562-577.

[29] A. Cazzani, M. Malagù, E. Turco, Isogeometric analysis: a powerful numerical tool for the elastic analysis of historical masonry arches, Contin. Mech. Thermodyn. 28 (1) (2016) 139-156

[30] A. Cazzani, M. Malagù, E. Turco, F. Stochino, Constitutive models for strongly curved beams in the frame of isogeometric analysis, Math. Mech. Solids 21 (2) (2016) 182-209.
[31] A. Bilotta, G. Formica, E. Turco, Performance of a high-continuity finite element in three-dimensional elasticity, Int. J. Numer. Methods Biomed. Eng. 26 (2010) 1155-1175.

[32] L. Greco, M. Cuomo, B-Spline interpolation of Kirchhoff-Love space rods Comput. Methods Appl. Mech. Eng. 256 (2013) 251-269.

[33] L. Greco, M. Cuomo, An implicit $G^{1}$ multi patch B-spline interpolation for Kirchhoff-Love space rod, Comput. Methods Appl. Mech. Eng. 269 (2014) $173-197$.

[34] L. Greco, M. Cuomo, An isogeometric implicit G1 mixed finite element for Kirchhoff space rods, Comput. Methods Appl. Mech. Eng. 298 (2016) 325-349.

[35] A. Cazzani, F. Stochino, E. Turco, An analytical assessment of finite elements and isogeometric analysis of the whole spectrum of Timoshenko beams, Z. für Angew. Math. Mech. (2016) 1-25, http://dx.doi.org/10.1002/zamm. 201500280.

[36] D.J. Steigmann, M.G. Faulkner, Variational theory for spatial rods, J. Elast. 33 $(1-26)(1993)$.

[37] A. Misra, P. Poorsolhjouy, Granular micromechanics based micromorphic model predicts frequency band gaps, Contin. Mech. Thermodyn. 28 (1) (2016) 215-234.

[38] J. Altenbach, H. Altenbach, V.A. Eremeyev, On generalized Cosserat-type theories of plates and shells: a short review and bibliography, Arch. Appl. Mech. 80 (1) (2010) 73-92.

[39] V.A. Eremeyev, W. Pietraszkiewicz, Material symmetry group and constitutive equations of micropolar anisotropic elastic solids, Math. Mech. Solids (2015), http://dx.doi.org/10.1177/1081286515582862.

[40] F. Dos Reis, J.F. Ganghoffer, Construction of micropolar continua from the asymptotic homogenization of beam lattices, Comput. Struct. 112 (2012) 354-363.

[41] K. Elnady, F. Dos Reis, J.-F. Ganghoffer, Construction of second order gradient continuous media by the discrete asymptotic homogenization method, Int. J. Appl. Mech. (2014).

[42] F. Tedesco, A. Bilotta, E. Turco, Multiscale 3D mixed FEM analysis of historical masonry constructions, Eur. J. Environ. Civil Eng. (2016), http://dx.doi.org/10. 1080/19648189.2015.1134676.

[43] E. Turco, Tools for the numerical solution of inverse problems in structural mechanics: review and research perspectives, Eur. J. Environ. Civil Eng. (2016) 1-46, http://dx.doi.org/10.1080/19648189.2015.1134673.

[44] A. Bilotta, E. Turco, A numerical study on the solution of the Cauchy problem in elasticity, Int. J. Solids Struct. 46 (2009) 4451-4477.

[45] A. Bilotta, A. Morassi, E. Turco, Reconstructing blockages in a symmetric duct via quasi-isospectral horn operators, J. Sound Vib. 366 (2016) 149-172.

[46] A. Bilotta, E. Turco, Numerical sensitivity analysis of corrosion detection, Math. Mech. Solids (2014) 1-17, http://dx.doi.org/10.1177/ 1081286514560093.

[47] G. Alessandrini, A. Bilotta, G. Formica, A. Morassi, E. Rosset, E. Turco, Evaluating the volume of a hidden inclusion in an elastic body, J. Comput. Appl. Math. 198 (2) (2007) 288-306.

[48] G. Alessandrini, A. Bilotta, A. Morassi, E. Turco, Computing volume bounds of inclusions by EIT measurements, J. Sci. Comput. 33 (3) (2007) 293-312.

[49] E. Turco, Identification of axial forces on statically indeterminate pin-jointed trusses by a nondestructive mechanical test, Open Civil Eng. J. 7 (2013) 50-57.

[50] F. Buffa, A. Cazzani, A. Causin, S. Poppi, G.M. Sanna, M. Solci, F. Stochino, E. Turco, The Sardinia Radio Telescope: a comparison between close range photogrammetry and FE models, Math. Mech. Solids (2015) 1-22, http://dx. doi.org/10.1177/1081286515616227.

[51] F. Stochino, A. Cazzani, S. Poppi, E. Turco, Sardinia Radio Telescope finite element model updating by means of photogrammetric measurements, Math. Mech. Solids (2015) 1-17, http://dx.doi.org/10.1177/1081286515616046. 